\title{
EXCLUSÃO-INCLUSÃO: CIRCULARIDADE PERVERSA NO BRASIL CONTEMPORÂNEO
}

\author{
EXCLUSION-INCLUSION: VICIOUS CIRCULARITY IN CONTEMPORARY BRAZIL
}

EXCLUSIÓN-INCLUSIÓN: CÍRCULO PERVERSO EN EL BRASIL CONTEMPORÁNEO

Zilma Fonseca $^{1}$

Resumo $\mathrm{O}$ texto aborda as intencionalidades e os desdobramentos teóricos e políticos do uso do termo 'exclusão' e sua contraparte, a inclusão. Discute o estatuto conceitual da expressão 'exclusão social', sua vinculação com uma 'nova questão social' e conceitos como cidadania e pobreza. Aponta a potencialidade explicativa e transformadora da utilização do conceito de 'expropriações secundárias' para a reflexão acerca da diversidade de situações sociais contemporâneas que expressam a desigualdade estrutural do sistema capitalista. Busca situar o debate sobre questões que se articulam com a noção de exclusão social, como o fim da centralidade do trabalho, a nova morfologia da classe trabalhadora e a composição do exército de reserva. Conclui desdobrando questionamentos que atualizam a demanda de aprofundamento de categorias marxianas fundamentais.

Palavras-chave exclusão social; políticas inclusivas; expropriações secundárias; exército de reserva; centralidade do trabalho.
Abstract This essay addresses the intentions and theoretical and political developments surrounding the use of the term 'exclusion' and its counterpart, inclusion. It addresses the conceptual statute of the expression 'social exclusion' and its association with a 'new social issue' and concepts such as citizenship and poverty. It points to the potential explanatory, transformative use of the concept of 'secondary expropriations' to reflect on the diversity of contemporary social situations that express the structural inequality of the capitalistic system. Additionally, it seeks to pinpoint the debate on issues that are linked with the notion of social exclusion, such as the end of the centrality of work, the new morphology of the working class, and the composition of the reserve army. It concludes by breaking down questions that update the demand for the deepening of fundamental Marxian categories. Keywords social exclusion; inclusive policies; secondary expropriations; reserve army; centrality of work. 


\section{Introdução}

Com a chegada ao poder do Partido dos Trabalhadores, em 2003, a diretriz de inclusão social torna-se elemento homogêneo das políticas públicas brasileiras, amparada no recurso ideológico da 'participação social' e sustentada por referências centradas na noção de exclusão social. As estratégias de inclusão social passam a fazer parte estruturante do corpo das políticas públicas implementadas nas áreas sociais e em áreas consideradas estritamente técnicas como, por exemplo, a ciência e tecnologia, conformam o apêndice social das políticas, enunciando um desenvolvimento social conjugado ao desenvolvimento econômico.

No plano internacional, o capitalismo mundializado, ao sustentar o processo de reestruturação produtiva, provocando disponibilização cada vez maior da força de trabalho, o aprofundamento das desigualdades e a expropriação de direitos conquistados, acarreta agudização alarmante das péssimas condições de trabalho e vida do conjunto dos trabalhadores.

Muitos são os autores, nacionais e estrangeiros, que, ao abordarem de forma mais teórica ou pragmática esses fenômenos sociais, os circunscrevem no âmbito da temática da exclusão social, assumindo o binômio político da exclusão-inclusão, cujo aprofundamento teórico justifica-se assim como o ponto nevrálgico deste ensaio.

\section{Exclusão social: dubiedade e imprecisão na nova questão social}

A partir da década de 1990, no Brasil, o termo exclusão social passa a ser usado nas reflexões de diversos pesquisadores sociais e, de forma ampla e crescente, na arena das políticas públicas, ganhando destaque na esteira do combate à pobreza.

Uma primeira discussão que se estabelece nos trabalhos sobre 'exclusão social' é sobre seu estatuto conceitual. É bem verdade que, mesmo reconhecendo a limitação teórica do termo, autores como Alves e Escorel (2012), Sawaia (2001) e Nascimento (1994) lançam-se na tarefa de contribuir para o seu aprimoramento teórico.

Por outro lado, há autores, como Zioni (2006), que refletem sobre o status metodológico do termo e reconhecem que exclusão social é uma noção de caráter metodológico apropriada pelas políticas públicas. Ou, como Frigotto (2010), que também não considera que exclusão social se constitua num conceito, porque "não apreenderia as mediações constitutivas da materialidade histórica atual da forma capital, cujo escopo é de ampliação e radicalização da sua natureza intrínseca - a desigualdade" (Frigotto, 2010, p. 419, grifo do autor). 
A constatação praticamente unânime acerca da ambiguidade e imprecisão do termo, e mesmo de suas especificidades históricas e nacionais, não se apresenta como um empecilho ao seu uso por intelectuais de renome e não arrefece nem a tentativa de aprimorá-lo nem o ânimo acadêmico de torná-lo ferramenta científica.

No Brasil, alguns trabalhos foram desenvolvidos no esforço de enunciação da exclusão como um processo dinâmico de muitas dimensões, procurando explicitar não somente os estados de exclusão, mas traçar trajetórias de exclusão - como desenvolveu Escorel (1999), assim como Sposati et al. (2002) e Pochmann (2004) que em seus trabalhos enunciam e georreferenciam indicadores, no propósito de expressar cientificamente um índice de exclusão/inclusão social.

Aprimorar as descrições das situações 'de exclusão', suas escalas e registros, seu crescimento e sua redução, estabelecer critérios e índices obrigam a focalizar o olhar sobre alguma dimensão particularizada e pode acrescentar riqueza de especificidades ao estudo. Entretanto, não substitui a necessária perspectiva do conjunto do processo econômico e social. O estabelecimento de critérios rigorosos que racionalizam de forma sofisticada uma ideia não a torna um instrumento efetivo de compreensão da realidade, visto que o método não prescinde da teoria.

Compreendemos que exclusão social é termo que, referido a fenômenos com origem, processos e bases fundamentais significativamente diferentes, funda-se numa impressão generalizante acerca desses fenômenos e não oferece suporte para discernimento e aprofundamento de suas determinações, especificidades históricas, econômico-sociais e políticas, não se constituindo como instrumento do pensamento para conhecimento da realidade. Ao contrário, contribui para obscurecer as relações de exploração e dominação que sustentam os fenômenos nomeados e para sustentar as formulações neoliberais que tomam corpo concreto nas políticas públicas contemporâneas.

Na década de 1960, o termo exclusão era já utilizado na França, referido ao fenômeno de marginalidade que se observava nas sociedades contemporâneas. Na década de 1970, o livro Os excluídos: um em cada dez franceses, do francês René Lenoir, passa então a ser considerado o marco do termo exclusão social, com uma conotação mais semelhante à contemporânea de inadaptação social (Zioni, 2006).

Essa nova conotação do termo exclusão emplaca numa conjuntura europeia recessiva, quando a crise do Estado de Bem-Estar Social sacudiu as referências políticas e sociais. Intelectuais e políticos que, até então, conseguiam explicar o peso das expropriações promovidas pelo capital como uma carga projetada apenas sobre os diferentes, os estrangeiros e os inadaptados, foram obrigados a admitir esse peso visivelmente recaindo sobre contingentes de trabalhadores até então absolutamente integrados. 
A impossibilidade de considerar o aumento da miséria e seus fenômenos correlatos como elemento de caráter residual favorece o surgimento de abordagens que, ao compreenderem essas novas condições para além da esfera da produção, chegam mesmo a identificar a necessidade de novos paradigmas que substituam referências como a centralidade do trabalho e a divisão da sociedade em classes sociais.

A reflexão sobre o fenômeno é, então, elaborada em termos de uma 'nova pobreza', provocada pelo crescente desemprego e mal amparada em face da fragmentação do aparato de proteção social existente. Assim, a exclusão social é temática que espalha sua influência para outros continentes, enunciada como categoria central de uma 'nova questão social', cujo novo paradigma social se opõe ao paradigma das classes sociais.

No Brasil, alguns autores alinham-se ao discurso de enunciação de um novo paradigma. Ao sugerirem mudança no modo de produção, compreendem que as relações centrais são outras. Para Guareschi (2001), a dominação e a exploração não são mais as relações centrais da sociedade, como no modo de produção capitalista, visto que as pessoas estão sendo excluídas do trabalho, da produção. Ou ainda, como defende Nascimento (1994), entendem que ocorreu uma mudança na natureza da questão social, que abandona a questão operária e assume a restrição à exclusão social.

Seja a discussão apresentada em termos de nova questão social ou deslocamento da questão social, a ênfase se coloca na impossibilidade de conceitos até então utilizados largamente conseguirem responder à existência de novos fenômenos, de novas formas sociais. Os autores que propugnam a afirmação de um novo paradigma são explícitos em apontar precisamente aquilo que deve ser substituído: a centralidade do trabalho e a luta de classes.

Contrapondo-se à enunciação de uma nova questão social e reafirmando o primado da intensificação da exploração do capital, afirma categoricamente José Paulo Netto (2010):

De fato, inexiste qualquer nova 'questão social'. O que se deve investigar, para além da permanência de manifestações 'tradicionais' da 'questão social', é a emergência de novas expressões da 'questão social' que é insuprimível sem a supressão da ordem do capital. A dinâmica societária específica desta ordem não só põe e repõe os corolários da exploração que a constitui medularmente; como já sugeri, a cada novo estágio do seu desenvolvimento, ela instaura expressões sociopolíticas diferenciadas e mais complexas, correspondentes à intensificação da exploração que é a sua razão de ser (Netto, 2010, p. 10).

Compreendemos que a relação capital-trabalho é uma relação desigual que se impõe ao conjunto das relações sociais, nos âmbitos econômico-produtivo, político-social e simbólico-cultural. Assim, encontramos em todos esses âmbitos formas de segregação, opressão, estigmatização, expropriação. 
Mesmo que alguns fenômenos vinculados a essas formas venham a ocorrer apenas mais recentemente, isso não substitui o sistema do capital e não lança bases estruturais que demandem um novo paradigma.

\section{Exclusão social: pobreza e cidadania}

Dentre os trabalhos que utilizam o termo exclusão social, uma vertente expressiva passa a ser a sua associação com as questões referentes ao conceito de cidadania - marcando sua ausência, sua negação e a necessidade de sua compreensão como o direito a ter direitos, como defendem Veras (2001), Sposati (1998) e Wanderley (2001).

O discurso da cidadania, inseparável da democracia, carrega também a reificação dos apregoados ideais de liberdade e igualdade, que obscurece sua base classista e facilita o estabelecimento de alianças e acordos de colaboração entre as classes - voltados para o 'bem comum'.

Esse é um pensamento bastante difundido, até mesmo em círculos considerados marxistas, e é neste círculo que nossas reflexões sobre a questão da cidadania na sociedade brasileira podem e devem ser aprofundadas.

Encontramos, ainda, no seio da autodenominada esquerda argumentos que se contrapõem à colaboração de classes e se posicionam radicalmente a favor de uma cidadania efetivamente plena, entendendo-a como não alcançável no sistema capitalista e constituindo, então, uma tarefa a ser realizada historicamente pela classe trabalhadora.

A (in)compreensão que subjaz a essas formulações é de que a parte (cidadania plena - emancipação política) pode ser tomada pelo todo (emancipação humana). Por mais radical, ampla e plena que seja a proposição, os radicais direitos de cidadania inscrevem-se no arcabouço da democracia e não chegam perto de questionar a expropriação básica existente na relação que funda a sociedade capitalista: a relação capital-trabalho.

A fragilidade principal desses argumentos está em admitir que a sociabilidade organizada e dirigida pelo capital não precisa ser substituída pela construção de outra sociabilidade e que pode ser aperfeiçoada pelo exercício da democracia.

Sem desconsiderar a importância existente na conquista das classes trabalhadoras na resistência contra as expropriações secundárias dirigidas pelo capital, no avanço dos direitos sociais e políticos, entendemos que é na luta contra a relação-capital, alinhada à emancipação humana como horizonte revolucionário, que a classe trabalhadora pode ultrapassar as possibilidades máximas colocadas no âmbito do capitalismo.

Além de grande imprecisão e ambiguidade, o termo tem também longevidade. Sobreposto à problemática da pobreza, é usado em situações e 
contextos os mais diferentes, apontando situações específicas de privações e estigmatizações diversas, englobando noções de carência e vulnerabilidade. De uma forma mais elaborada, é abordado como um processo que expressa contradições do desenvolvimento da sociedade capitalista que impede ou dificulta a integração de certos grupos da população.

Alguns autores, como Wanderley (2001), emitem alerta no sentido de não considerar os dois termos como sinônimos, entretanto, no campo da ação pública, os termos são considerados até mesmo intercambiáveis, como apresentam Carneiro e Costa (2003).

Certamente, pobreza e exclusão social são termos que privilegiam o campo da política como âmbito de compreensão e superação da crônica problemática social provocada pela expansão e acumulação do capital.

Pochmann (2004) é mais um autor que se referencia na política para tratar da exclusão e da pobreza. Entende que, sem consolidação da experiência democrática, o que temos vivenciado no país é não só concentração da renda como principalmente concentração do poder. Considera que o "processo de exclusão social no Brasil está ligado umbilicalmente com a concentração de poder", que a "pobreza no país é de natureza política" e que o "maior desafio da política social no Brasil é democratizar a democracia representativa" (Pochmann, 2004, p. 14).

A 'democracia participativa' assume papel importante nos governos neoliberais, a partir da reforma do Estado, em 1995, com a adoção de uma 'administração gerencial', nos termos elaborados por Bresser-Pereira (1998), ao propor, entre outros mecanismos, o 'controle social direto' das unidades descentralizadas executoras das políticas públicas.

Ao mesmo tempo, a identificação do indivíduo como 'cidadão' de direitos e a difusão de uma valoração da sociedade civil como guardiã desses direitos obscurecem as condições fundamentais que definem as relações de produção e as desigualdades de classe.

Pela vertente da similitude entre exclusão e pobreza, recaímos mais uma vez nos ideais de cidadania, variando nas expressões dos autores, seja em termos de cidadania plena, democratização da democracia, cidadania política, cidadania social, cidadania cívica, cidadania fragmentada ou hierarquizada, cidadania excludente ou vários outros - o que nos remete às considerações feitas sobre o tema, em linhas anteriores.

\section{Inclusão social}

O termo 'inclusão social', de forma semelhante à bandeira ideológica da 'superação da pobreza', sem vinculação explícita às dificuldades estruturais existentes, apresenta-se também como absolutamente autoexplicativo. 
Para Steren dos Santos (2001) e Sawaia (2001), o binômio exclusão-inclusão expressa uma relação dialética, entendida como forças opostas em constante interação, capaz de substituir a simples ideia de exclusão.

Entretanto, neste binômio, apenas formalmente um termo é a negação do outro. O par exclusão-inclusão forma os dois lados de uma mesma moeda, da lógica de exploração e dominação do capital. É um círculo fechado que se alimenta de si mesmo, tratando-se na verdade de um círculo vicioso, pois pressupõe a reprodução incessante do fenômeno assim como a incessante reprodução ilusória de sua solução. Não existe oposição entre os termos, pois, na lógica que constitui o binômio, eles são absolutamente complementares - a mesma circularidade perversa do movimento do capital.

O genérico e indefinido rótulo de 'excluídos' passa a ser referido às minorias étnicas, aos negros, aos sem-teto, aos velhos e jovens, às mulheres e crianças, aos desempregados e subempregados, aos homossexuais, aos portadores de necessidades especiais, aos miseráveis - um elenco interminável de situações de origens e naturezas históricas diversas.

As políticas inclusivas podem abarcar um espectro amplo de ações de geração de renda, de tecnologias sociais, artístico-culturais, educacionais e desportivas, entre outras, e podem também ser compreendidas e implementadas no sentido de se contraporem a práticas discriminatórias que se materializam nas instituições.

Como o fenômeno social de degradação das situações de trabalho e vida das classes trabalhadoras é considerado de modo aleatório, multifacetado e fragmentado, as políticas traçadas para seu enfrentamento são também não sistêmicas, focalizadas e parcamente compensatórias. As chamadas políticas inclusivas apresentam-se de forma desconectada da noção de trabalho e vinculadas à perspectiva de cidadania.

\section{Os chamados 'excluídos'}

Em relação aos 'excluídos', podemos resumir os dois traços principais que circulam na literatura sobre exclusão social: o primeiro é a impossibilidade de serem absorvidos pelos novos processos produtivos, em razão do seu crescimento numérico e da ausência das habilidades requeridas; e o segundo relaciona-se ao estigma que sobre eles se abate e que pode ter como consequência sua expulsão da 'órbita da humanidade'.

Outros autores engrossam a mesma avaliação acerca da condição de 'descartáveis' e dos riscos de eliminação, até mesmo física, dos 'excluídos socialmente'. Segundo Leal (2004), em estudo que recupera, no período 1996-2006, o debate sobre exclusão social, autores como Buarque, Nascimento 
e Wanderley aparecem como defensores da ideia de que os grupos excluídos se tornam desnecessários do ponto de vista da economia capitalista.

Fontes [2007] chama a atenção para a devastação que a expansão do capital-mercadoria ou monetário no plano internacional provoca atualmente, em especial o acirramento da contradição entre a socialização da força de trabalho e a concentração internacional do capital.

A eliminação de trabalhadores ocorre, no momento atual de concentração do capital, com maior frequência e magnitude, seja por meio de conflitos de classe - como constatamos no caso dos conflitos rurais ou fruto da violência social -, seja por meio da fome e de endemias. O fato é que se amplia a força destrutiva e autodestrutiva do capital.

Certamente, o impulso do capital para a eliminação do trabalho é componente fundamental de suas contradições internas, visto que sua existência depende da existência do trabalho. Assim, tal impulso, constituinte de sua dinâmica e metabolismo, possui o limite máximo de sua própria sobrevivência. Nesse intervalo, a única direção que prevalece é sua cega necessidade de expansão, acumulação e controle de toda reprodução social - um movimento destrutivo e autodestrutivo que, portanto, produz incessantemente suas próprias contradições e crises.

\section{A centralidade do trabalho}

A centralidade do trabalho e as implicações teórico-políticas do conceito de exército industrial de reserva são campos de discussão que necessariamente se apresentam referidos à temática da 'exclusão social'. Procurando não extrapolar os objetivos e o alcance propostos por este ensaio, nosso esforço é de situar, minimamente, essa discussão sem pretensão de esgotar questões tão amplas e complexas.

As teses que apregoam o fim do trabalho assumem, segundo Nun (2000), versões diferenciadas: a tecnológica enfoca o trabalho como fator de produção que, com o avanço da tecnologia, está sendo eliminado; a filosófica, com foco na coesão social, reflete sobre como poderia a sociedade manter-se estruturada em torno do trabalho, se já não assegura o pleno emprego aos seus membros; e a sociológica, que fundamenta as políticas de inclusão, parte do pressuposto de que, na impossibilidade de restaurar o chamado pleno emprego, o importante é tornar sua ausência tolerável àqueles que a sofrem.

José Nun, um dos expoentes da teoria de marginalidade latino-americana, inaugurou, no final dos anos 1960, um olhar diferenciado dos outros teóricos dessa vertente, com a formulação do conceito de massa marginal. Cerca de três décadas depois, o autor publica um trabalho onde revisa e expande seus próprios argumentos. Suas ideias se articulam com a discussão 
posta em pauta pela 'nova exclusão', referente à existência de um contingente populacional que seria desnecessário economicamente, perigoso socialmente, e assim, passível de eliminação. Em trabalho datado de 2000, Nun define essa população como "massa marginal", isto é, um contingente de trabalhadores que, na fase monopolista do capital, torna-se um excedente populacional que ultrapassa o exército industrial de reserva, sendo, portanto, não funcional para a economia capitalista (Nun, 2000).

Procurei mostrar que em muitos lugares, ao contrário, crescia uma população excedente que, no melhor dos casos, era simplesmente irrelevante para o setor hegemônico da economia e, na pior das hipóteses, se convertia em perigo para sua estabilidade (Nun, 2000, p. 49, grifos nossos).

É inegável que o conjunto de transformações pelos quais passa o sistema-capital na contemporaneidade, contexto no qual se destaca a chamada reestruturação produtiva e a flexibilização do trabalho, traz como aspectos principais, não apenas novas formas de precarização do trabalho, mas também o aumento do desemprego crônico - o que certamente repercute em termos da vida e da vivência cotidiana e subjetiva dos trabalhadores.

Este quadro econômico-social de desemprego estrutural crescente, com um cotidiano de trabalho, agora então, marcado pela flexibilização, suscita formulações que não diferenciam o possível fim do trabalho assalariado formal com o fim do trabalho assalariado. Nesse caminho, alguns autores enunciam não somente o fim da centralidade do trabalho, mas também a perda da importância da classe trabalhadora e, até mesmo, o fim das classes e da luta de classes.

Como efetivamente não se trata do iminente fim do modo de produção capitalista, essas teorizações contribuem para a construção de uma ideologia fatalista de perenidade do capital, da aceitação da sua sociabilidade como a única forma possível de existência e da impossibilidade de a ele resistir e lutar. Mais uma vez, em condições conjunturais que colocam a classe burguesa em posição hegemônica privilegiada em face da classe trabalhadora, proliferam estudos que buscam comprovar que não há saída substitutiva do sistema capital e que nem mesmo existe esse tipo de interesse na sociedade - já então considerada esvaziada de sua composição classista.

Analisando as dimensões da reestruturação produtiva² e aprofundando o estudo sobre as metamorfoses do trabalho na contemporaneidade, Giovanni Alves (2007) afirma a insustentabilidade da tese de fim da centralidade do trabalho na vida social:

Alguns apontam o desemprego como sendo expressão da perda de centralidade do trabalho na vida social. Pelo contrário, o desemprego é tão somente a explicitação 
negativa plena da condição irremediável do regime do salariato. O desemprego problematiza, no plano da demanda, a condição de vendabilidade da força de trabalho como mercadoria. O desemprego do trabalho vivo só é problema porque o regime do salariato é seu pressuposto. Só existe (ou deveria existir) demanda por força de trabalho porque existe (e é necessário que ocorra) oferta de força de trabalho como mercadoria no mercado de trabalho. O que denominamos de 'crise do trabalho' é a plena afirmação do regime do salariato (Alves, 2007, p. 86-87).

Contrapondo-se também a essa tese, Fontes (2010) articula as expropriações secundárias, contemporâneas à situação de disponibilização dos trabalhadores, que situa como uma "exasperada disponibilidade ao mercado":

Menos, portanto, do que um retorno a formas arcaicas, as novas expropriações (somadas à permanência das expropriações primárias) demonstram que, para a existência do capital e sua reprodução, é necessário lançar permanentemente a população em condições críticas, de intensa e exasperada disponibilidade ao mercado. Em que pesem as intervenções de neoconservadores ou de pós-modernos, que consideraram terminada a época do "trabalho", a velocidade e extensão das expropriações dizem o contrário (Fontes, 2010, p. 47).

A força de trabalho é mercadoria na sociedade capitalista e a crise deste mercado configura-se também como contratendência à queda da taxa de lucro, provocada pela expansão e acumulação do capital, e acarreta um contingente de trabalhadores excedentes para além mesmo do exército industrial de reserva, pressionando para baixo o valor da força de trabalho.

Na discussão sobre a centralidade do trabalho, buscamos destacar a importância de se abrir a reflexão, em especial junto aos trabalhadores, acerca não só da real e efetiva centralidade do trabalho - e suas implicações na contemporaneidade - como da possibilidade da classe trabalhadora, como exército ativo ou superpopulação relativa, se constituir como classe para si, sujeito da sua própria história e alavanca da sua emancipação e da emancipação da humanidade. Uma história que é construída a partir do lugar social onde estamos, nas condições em que nos encontramos, mesmo em circunstâncias extremamente adversas, como a que estamos vivenciando no atual período histórico que registra severas derrotas da classe trabalhadora.

\section{Trabalhadores excedentes}

Procuremos compreender um pouco melhor as realidades a que muitos conceitos relacionados à dinâmica populacional e trabalhadores excedentes, sob o modo de produção capitalista, fazem referência. Em se tratando de 
dinâmica populacional, uma explicação que facilmente pode impregnar-se no senso comum é a explicação malthusiana de que o aumento da população é sempre muito maior do que o aumento dos meios de subsistência, o que geraria a fome e a miséria em uma sociedade.

Na verdade, essa compreensão malthusiana assume um caráter abstrato e metafísico visto que naturaliza o crescimento populacional humano passível apenas de ser limitado pela produção dos meios de subsistência e ignora que a dinâmica populacional é diferente nas diferentes sociedades e épocas históricas.

Em estudo sobre a teoria da população em Marx, Viana (2006) destaca que, segundo observação de Marx, David Ricardo já havia esclarecido que não é a quantidade de 'meios de subsistência' e sim os meios de emprego que produzem a população excedente. E acrescenta que, segundo o próprio Marx, a criação de 'trabalhadores excedentes' (homens desprovidos de propriedade que precisam trabalhar para sobreviver) "é própria da época do capital" (Marx apud Viana (p. 92, 2006).

Seguramente, todo modo de produção produz uma população excedente, mas, numa perspectiva marxiana, cada modo de produção gera uma dinâmica populacional própria. Nesse sentido, população excedente é um conceito histórico que abrange os modos de produção existentes na história da organização social dos homens.

Para Viana (2006), pautando-se em citação de Marx, essa população excedente é identificada como a superpopulação relativa. O autor compreende que, sob o sistema capital, mesmo em sua fase monopolista, a superpopulação relativa exerce uma funcionalidade estrutural, e nesse sentido as definições se equivalem: “Esta população 'excedente' Marx chama de 'superpopulação relativa'." "Ela constitui um exército industrial de reserva disponível, que pertence ao capital de maneira tão absoluta, como se ele o tivesse criado à própria custa" (Marx apud Viana, p. 94, 2006).

A relação dessa população excedente com a expansão e a acumulação do capital, no período de constituição do sistema capitalista, conta com as expropriações primárias para ajudar a garantir o contingente de força de trabalho necessário à implantação do novo modo de produção - num enorme movimento de absorção que não distinguia jovens, idosos, mulheres ou crianças. O desenvolvimento da industrialização com suas oscilações e ciclos característicos passam a influenciar fortemente tanto a absorção como a reprodução da superpopulação.

No regime capitalista, capital e trabalho estão inextricavelmente relacionados. A expansão do capital não pode ser pensada sem a expansão da força de trabalho, mesmo que em relação ao capital constante a sua proporção seja cada vez menor. Os mesmos fatores que provocam a expansão do capital provocam também o aumento do exército industrial de reserva, 
conforme Carcanholo e Amaral (2007) explicitam com base na lei geral da acumulação capitalista, valendo-se de citação de Marx, aqui transcrita:

Quanto maiores a riqueza social, o capital em função, a dimensão e energia de seu crescimento e consequentemente a magnitude absoluta do proletariado e da força produtiva de seu trabalho, tanto maior o exército industrial de reserva. A força de trabalho disponível é ampliada pelas mesmas causas que aumentam a força expansiva do capital. A magnitude relativa do exército industrial de reserva cresce portanto com a potência da riqueza, mas, quanto maior esse exército de reserva em relação ao exército ativo, tanto maior a massa da superpopulação consolidada, cuja miséria está na razão inversa do suplício de seu trabalho. E, ainda, quanto maiores essa camada de lázaros da classe trabalhadora e o exército industrial de reserva, tanto maior, usando-se a terminologia oficial, o pauperismo (Marx, 1974, p. 747 apud Carcanholo e Amaral, 2008, p. 171).

Ferraz, segundo transcrição de nota de rodapé extraída de texto de Marx, explicita a função do termo italiano lazzaroni: “alcunha dada em Itália aos lúmpemproletários, aos elementos desclassificados; os lazzaroni eram frequentemente utilizados pelos círculos monárquico-reaccionários na luta contra o movimento democrático e liberal (Marx, 1981, p. 85 apud Ferraz, 2010, p. 82).

Esta explicitação nos auxiliará, mais à frente, a compreender o debate que ocorre em relação à conformação do exército de reserva e à posição ocupada por um quantitativo crescente de trabalhadores exasperadamente disponibilizados pelo capital.

Os movimentos do capital relacionam-se com as conformações no campo do trabalho, com a produção da força de trabalho, visto a ligação vital, e fundamentalmente contraditória, que existe entre ambos. A dinâmica do capital - sua produção, expansão, acumulação e concentração - é, portanto, o que gera a proporção entre a população ativa e a superpopulação relativa.

Certamente o crescimento do capital global redunda em crescimento do capital variável, isto é, da força de trabalho que o compõe, mas é também certo que isto ocorre de forma contínua e proporcionalmente decrescente. A quantidade de equipamentos e máquinas empregada na produção aumenta sem que a contratação de trabalhadores se amplie na mesma proporção.

Como um de seus movimentos constantes no sentido de desvalorizar o trabalho vivo, o capital produz trabalho vivo em excesso - enquanto força de trabalho disponível para o seu consumo - criando uma superpopulação relativa ou exército industrial de reserva (Alves, 2007).

Considerar sinônimos, equivalentes, exército industrial de reserva e superpopulação relativa faz parte de uma polêmica no debate atual sobre o tema e traz implicações que tornam mais ou menos desconfortável, para 
autores que se utilizam de algumas categorias marxistas em seus estudos, a utilização da noção de exclusão social.

Como vimos no parágrafo mais acima, há autores, como Alves, que mesmo sem aprofundar especificamente esta questão, utilizam os dois termos como sinônimos, sem abrir questionamentos.

Outros autores entram no debate e buscam aprofundar suas bases teóricas em relação a essas questões. Em trabalho já citado, Viana contrapõe-se à ideia de Nun de que não se deve considerar todo o excedente da população como exército de reserva, pautando-se numa ideia de 'função' em que, sobre a dinâmica da acumulação, o exército industrial de reserva produziria efeitos funcionais e os efeitos não-funcionais seriam atribuídos ao que ele denominou "massa marginal".

Viana considera que Nun parte da premissa correta baseada na historicidade dos conceitos, que compreende superpopulação relativa como aquela existente em vários modos de produção e exército industrial de reserva existente somente no capitalismo. Segundo Viana, o que Nun desconsidera e, portanto, se equivoca, é que: "Para Marx, superpopulação relativa e exército industrial de reserva são, no capitalismo, a mesma coisa" (Viana, 2006, p. 1.019). Prossegue Viana, contrapondo-se a esses argumentos sobre efeitos funcionais e não funcionais, argumentando que "a concepção de Nun não consegue comprovar que tal distinção contribui para um melhor entendimento da superpopulação relativa e nem que a chamada "massa marginal" seja disfuncional" (Viana, 2006, p. 1.019). Argumenta também Viana que tal distinção conceitual cria uma ilusão de demarcação que não existe, e que uma suposta parcela populacional disfuncional "só tem sentido numa concepção metafísica, que desconsideraria o caráter histórico, dinâmico, desta parte da população e provocaria o seu isolamento, desligando-a da totalidade concreta, procedimento tipicamente não-dialético" (Viana, 2006, p. 1.020).

Mesmo sem aprofundarmos grandemente o debate acerca dos efeitos funcionais do exército industrial de reserva sobre a acumulação do capital, compreendemos que a magnitude quantitativa desse contingente populacional e os aspectos culturais a ele relacionados não o situam como uma população, isolada da totalidade produzida pelo sociometabolismo do capital, mesmo em sua fase monopolista de capital-imperialismo.

Sobre a categoria exército industrial de reserva há também uma polêmica que se localiza na compreensão acerca de suas formas de manifestação na contemporaneidade, que gostaríamos de abordar, em virtude da sua relação com a ideia de um contingente populacional que se torna 'descartável' para a economia capitalista e alvo de representações que poderiam levar até mesmo à sua eliminação - como vimos na exposição do pensamento de inúmeros autores que utilizam a noção de exclusão social. 
Sobre a origem da categoria exército industrial de reserva, Ferraz (2010) atenta para o fato de que Marx, ao formulá-lo, referenciava-se numa realidade histórica em que esse excedente populacional era atraído para os polos industriais. Tratava-se, portanto, de uma força de trabalho para a indústria. O argumento é desenvolvido por Ferraz no sentido de legitimar o uso do termo exército de reserva: "A disponibilidade do trabalho não ocorre apenas neste setor, de modo que o qualitativo 'industrial' pode ser suprimido, pois o importante a destacar é a existência de trabalhadores disponíveis a contratações" (Ferraz, 2010, p. 74-75).

De modo geral, os autores estudados que se voltam para a discussão da superpopulação relativa ou exército de reserva, referenciados em Marx, reconhecem três formas de manifestação: superpopulação relativa líquida ou flutuante, que é compreendida como aquele contingente de trabalhadores que ora é atraído ora é repelido das unidades produtivas, em consequência dos ciclos econômicos do capital; superpopulação relativa latente, que se refere aos trabalhadores rurais que são repelidos pelo avanço do capital e não são absorvidos pela agricultura capitalista, encontrando-se no limiar de se tornarem parte do proletariado urbano; e superpopulação relativa estagnada, que compreende a parte do exército ativo de trabalhadores que, com uma ocupação irregular, trabalham ao máximo e são pagos com o mínimo possível.

Giovanni Alves (2007) admite as três manifestações acima mencionadas, porquanto parta do entendimento de que, como categoria social, a superpopulação relativa expressa a precariedade do trabalho assalariado. Alves utiliza o termo 'excluídos' num sentido econômico-político diferente daquele que predomina nos escritos dos autores que seguem a vertente 'resolutiva' da inclusão, pois considera que possuem uma função simbólica, vinculada à matriz sociometabólica do medo - que sedimenta os consentimentos dos proletários na produção de valor.

Carcanholo e Amaral (2008) analisam a acumulação capitalista e o exército de reserva na perspectiva das economias dependentes. Nesse trabalho, não utilizam a expressão lúmpemproletariado, mas, de forma bastante semelhante, consideram o pauperismo como uma quarta expressão da superpopulação relativa que englobaria 'aqueles que vivem em situações absurdas de miséria e indigência' e que seria absolutamente funcional ao capital.

Contrariamente, Ferraz (2010) afirma de modo claro sua compreensão de que, em Marx, o pauperismo não constitui mais uma manifestação da superpopulação relativa, mas é sim uma condição que perpassa o conjunto da superpopulação relativa, atingindo a superpopulação estagnada com maior intensidade e culminando na constituição de uma superpopulação consolidada - sobre a qual explicita: 
Ou seja, compõe o exército de reserva uma parcela de indivíduos que não mais sairá desse segmento da classe trabalhadora, que não mais venderá a sua força de trabalho diretamente a um capitalista de forma estável. A constituição dessa superpopulação consolidada é inerente ao próprio modo de produção capitalista (Ferraz, 2010, p. 79).

Alves (2007) vai localizar o contingente de proletários excluidos, a que se refere, no lúmpemproletariado ou pauperismo, entendido - à semelhança de Carcanholo e Amaral - como "contingente de homens e mulheres imersos na proletariedade extrema e cuja morfologia social é tão complexa quanto a do trabalho estagnado" (Alves, 2007, p. 108).

Viana (2006) contribui grandemente para a polêmica ao identificar o lúmpemproletariado com o exército industrial de reserva, isto é, o conjunto da superpopulação relativa constituída pelo capitalismo.

Ferraz (2010), contrariamente a Viana, compreende que o pauperismo não é condição suficiente para definir o lúmpemproletariado - "senão toda a classe trabalhadora estaria nele incluída", não podendo ser desconsiderado que à produção de riqueza num polo corresponde a produção da fome e da miséria nas classes trabalhadoras.

A autora entende que o lúmpemproletariado, na luta revolucionária, é um grupo que pode ser atraído às classes reacionárias. Sobre esse grupo, permite-se, também, ponderar que

[sua] característica determinante é menos sua posição e influência econômica no modo de produção capitalista do que as alianças, ações e apoios que este grupo politicamente estabelece com outras classes sociais, estas por sua vez com posição definida na Estrutura de Apropriação e Política da sociedade em questão, portanto, com interesses de classes definidos e menos fragmentários (Ferraz, 2010, p. 83).

Mais à frente a autora complementa seu pensamento, esclarecendo que, certamente, os interesses econômicos são a base das alianças políticas e que, nesse caso, situam-se na possibilidade de auferir maiores ganhos. E de forma contundente, conclui que:

Entendemos ser um equívoco considerar o lúmpemproletariado como sendo apenas uma parte marginal da classe trabalhadora que não possui consciência de classe nem poderá vir a desenvolvê-la. Este termo não pode ser, em virtude de sua complexidade e do contexto histórico em que esses grupos são constituídos e acionados, traduzido literalmente como os 'trapos do proletariado' ou como uma subclasse da população humana, conforme nos indicam o senso comum transmitido pelos dicionários e, muitas vezes, aceitos nos círculos de pessoas que se autodenominam comunistas (Ferraz, 2010, p. 84). 
A análise da realidade empírica certamente nos auxilia na compreensão das contradições existentes na relação capital-trabalho, no aumento quantitativo do exército de reserva e suas alterações qualitativas. Sem a pretensão de mergulho nessa realidade, propomo-nos a indicar aspectos, discutidos e analisados por diversos autores, que podem ser sinalizadores de condições, situações e relações que nos ajudem a chegar mais próximo dessa compreensão desejada.

Ricardo Antunes (2006), de uma forma despretensiosa, em entrevista para um sindicato de trabalhadores, aponta profundas mudanças na morfologia da classe trabalhadora. Identificando o desempregado como parte dessa classe, compreende-o inserido no exército industrial de reserva:

A classe trabalhadora hoje tem uma nova morfologia. Ela tem o proletariado industrial produtivo, que é o seu núcleo central. Esse proletariado não é mais aquele proletariado estável da era taylorista e fordista (...) ele é terceirizado, ele é precarizado. Essa é a classe trabalhadora hoje. E ela inclui também o desempregado. Porque o desempregado é consequência do desemprego estrutural, que resulta dessa lógica destrutiva do capital. Então, o desempregado não é desempregado porque ele quer. Ele é desempregado pelo capital. Ele é parte do que o Marx chamava de exército industrial de reserva. Nós podemos discutir a validade ou não da noção de exército industrial de reserva hoje. Eu penso que essa noção ainda é válida, mas é um debate. O que era um exército industrial menor, hoje é um exército monumental de reserva. Esta é a classe trabalhadora. Esta é a nova morfologia (Antunes, 2009).

Os trabalhos realizados pelos trabalhadores informais, já sobejamente estudados, mostram que o trabalho informal não apenas colabora para a expansão e reprodução do capital como também está integrado ao circuito da produção capitalista. Apenas como exemplo podemos citar o estudo realizado por Bosi (2008) sobre o trabalho dos catadores de recicláveis no Brasil, no período de 1985 a 2005. Nele, o autor explicita a integração desse trabalho à dinâmica do processo de produção capitalista e chama a atenção para o fato de que a suposta situação de exclusão dos catadores o qualifica para esse tipo de ocupação - num aparente paradoxo, visto que esses trabalhadores tiveram suas qualidades recusadas pelo 'mercado'.

Outro exemplo que podemos arrolar, localizado no setor da indústria têxtil, chega a apresentar condições de trabalho de semiescravidão para homens, mulheres e crianças brasileiros e latino-americanos. O exemplo da Zara, conhecida marca espanhola de vestuário feminino, mostra que a economia chamada 'subterrânea', em condições ilegais de produção e circulação (em outros casos, muitas vezes também de consumo), está articulada com a economia 'legal' das empresas transnacionais. No rol de atividades 
e inserções semelhantes, podemos mencionar a economia da exploração sexual, atividade produtiva realizada por adultos homens e mulheres e crianças, que movimenta altas cifras, assim como a conhecida atividade do jogo do bicho e do tráfico de drogas.

Cabe observar que a ilegalidade referida a essas situações é fruto exatamente das expropriações secundárias comandadas pelas necessidades de expansão e acumulação do capital. A relação social que funda o capitalismo, capital-trabalho, assenta-se sobre uma expropriação originária dos trabalhadores e a sua expansão e reprodução exige, conforme nos indica Fontes (2010),

a conservação e reprodução em escala sempre crescente de uma população dependente do mercado, disponível para a venda da força de trabalho de forma integral ou necessitando integrar-se ao mercado, total ou parcialmente, para subsistir (Fontes, 2010, p. 47).

A força de trabalho, sob o sistema do capital, quer esteja ou não inserida diretamente na produção, torna-se uma fonte de mais valia para a burguesia e para isto concorre grandemente as ações do Estado no sentido de dirigir e gerenciar as contratendências à queda da taxa de lucro e as políticas inclusivas. Políticas assentadas não só na ausência de garantia como também na constante perda de direitos adquiridos pela classe trabalhadora.

\section{Expropriações secundárias: uma nova abordagem}

Num trabalho intitulado $O$ imperialismo tardio: expropriações, trabalho, politica e cultura (2007), a historiadora Virginia Fontes parte da consideração de que a expropriação massiva dos trabalhadores é elemento fundamental da relação social subjacente ao capital e se reproduz em escala sempre crescente. Identifica novas formas de expropriação - as expropriações contemporâneas ou expropriações secundárias - e aprofunda a reflexão, compreendendo que tais expropriações são resultados da escala de concentração de capitais.

A partir de 2007, Fontes aprofunda a discussão sobre o capitalismo contemporâneo - incluindo o movimento estrutural das expropriações, que culmina com a publicação, em 2010, do livro O Brasil e o capital-imperialismo: teoria e história. Na sua conceituação de expropriações secundárias, Fontes nos possibilita compreender a contínua e crescente produção social de trabalhadores disponibilizados para o mercado:

Estas expropriações, que estou denominando disponibilizações ou expropriações secundárias, não são, no sentido próprio, uma perda de propriedade de meios de 
produção (ou recursos sociais de produção), pois a grande maioria dos trabalhadores urbanos dela já não mais dispunha. Porém, a plena compreensão do processo contemporâneo mostra terem se convertido em nova - e fundamental - forma de exasperação da disponibilidade dos trabalhadores para o mercado, impondo novas condições e abrindo novos setores para a extração de mais-valor. Este último é o ponto dramático do processo (Fontes, 2010, p. 54, grifos da autora).

A expropriação primária - expropriação de grandes massas campesinas ou agrárias atraídas pelo meio urbano, incapacitadas de manter sua reprodução ou expulsas de suas terras - desempenhou papel relevante na constituição do modo de produção capitalista e, como nos adverte a historiadora, continua no arsenal de movimentos do capital-imperialismo contemporâneo, juntamente com as expropriações secundárias.

A concentração de recursos sociais e as expropriações sociais constituem faces da tendência à expansão do capital. Das expropriações emanam as condições de possibilidade do capital e sua ampliação pressupõe também a ampliação das expropriações.

Abranger praticamente todas as dimensões da vida é uma característica contemporânea da expropriação que, sob variados aspectos, incide sobre um conjunto de direitos - demarcados pelos costumes, tradicionais, históricos, e abrange transformações profundas na cultura, na ideologia e na política.

Esse contingente de trabalhadores expropriados e, portanto, disponibilizados para o mercado, deparam-se com novas barreiras físicas, sociais e culturais através da segregação espacial, discriminações e opressões de vários matizes - dos quais, muitas vezes, buscam escapar através de imigração - e expressam de forma crua as profundas contradições desse processo de expropriação.

Considerar as manifestações dessa superpopulação relativa como fenômenos segmentados e repletos de especificidades tão variadas quanto variados são os matizes das discriminações e opressões dirigidas a esse contingente populacional e agrupá-las artificialmente sob a terminologia de 'excluídos' em nada contribui para compreender as causas estruturais de sua existência.

Assim como não contribui também para esclarecer que as variadas formas de segregação, estigmatização e representações sociais negativistas em relação aos trabalhadores disponibilizados pelas expropriações são, em última instância, formas de estratégias de concorrência criada pelo capital entre os assalariados, em face do número insuficientemente crônico de empregos existentes.

As expropriações secundárias, enquanto causa fundamental dos vários efeitos identificados por muitos autores como 'exclusão social', constituem um fenômeno permanente e necessário para a expansão e acumulação do 
capital e, nesse sentido, não pode ser superada pelo próprio capitalismo. No mesmo sentido, os trabalhadores que, disponibilizados pelas expropriações, sofrem os mais diversos tipos de discriminação e segregação e são alvos de representações negativistas por parte da sociedade não podem, também, ser descartados pelo capital.

É bastante generalizada a ideia de que um contingente cada vez maior de desapropriados pelo capital e disponibilizados para o mercado podem se tornar uma ameaça à coesão social. Coesão social que, confundida com apassivamento dos conflitos de classe, tem sustentado politicamente a produção das expropriações, das desigualdades e das estigmatizações. Essa ameaça latente impulsiona, certamente, a formulação de uma quase infinita miríade de iniciativas, programas e políticas públicas inclusivas que verificamos em curso no Brasil e que, efetivamente, contribuem para a hegemonia da classe burguesa.

Ignorar que as expropriações fazem parte inerente do movimento expansivo do capital, sustentado pelo Estado, e manter-se na superficialidade da noção de exclusão social colaboram para uma compreensão da situação como inusitada, como um desvio do capitalismo, e traz em si mesma o pressuposto de reformas e políticas que recoloquem o capitalismo no eixo correto.

Em direção contrária à difusão desta ilusão, identificamos essas situações sociais como vicissitudes da dinâmica perversa e socialmente dramática do capital - novas características expressas das expropriações.

O conceito de expropriações secundárias como instrumental de análise das situações de existência da superpopulação relativa desloca a reflexão para uma abordagem que instiga e possibilita a apreensão das contradições da realidade de forma que possa ser levado em consideração um conjunto maior de suas determinações. 
Resumen El texto aborda las intencionalidades y los despliegues teóricos y políticos del uso del término 'exclusión' y su contraparte, la inclusión. Discute el estatuto conceptual de la expresión 'exclusión social', su vínculo con una ;nueva cuestión social' y conceptos como ciudadanía y pobreza. Señala el potencial explicativo y transformador del uso del concepto 'expropiaciones secundarias' para reflexionar sobre la diversidad de situaciones sociales contemporáneas que expresan la desigualdad estructural del sistema capitalista. Trata de situar el debate sobre temas que se articulan con la noción de exclusión social, como el fin de la centralidad del trabajo, la nueva morfología de la clase obrera y la composición del ejército de reserva. Concluye con planteamientos que actualizan la demanda de profundización de categorías marxistas fundamentales.

Palabras clave exclusión social; políticas inclusivas; expropiaciones secundarias; ejército de reserva; centralidad del trabajo.

\section{Notas}

1 Fundação Oswaldo Cruz, Manguinhos, Rio de Janeiro, Brasil.

Mestre em Educação Profissional em Saúde pela Escola Politécnica de Saúde Joaquim Venâncio, Fundação Oswaldo Cruz. <zilmacfonseca@fiocruz.br>

Correspondência: Rua Rodolfo Dantas, 89, apartamento 503, CEP 22020-040, Copacabana, Rio de Janeiro, RJ, Brasil.

2 Para maior aprofundamento, ver Trabalho e subjetividade: o espírito do toyotismo na era do capitalismo manipulatório, de Giovanni Alves, Boitempo Editorial, 2011; e Adeus ao trabalho?: ensaio sobre as metamorfoses e a centralidade do mundo do trabalho, de Ricardo Antunes, Cortez e Editora da Unicamp, 2000.

3 A força de trabalho, quando ingressa no processo de produção capitalista, torna-se parte do capital, a parte chamada capital variável. Chama-se 'variável' porque apenas a força de trabalho, com seu trabalho vivo, é capaz de adicionar valor ao final do processo de produção. A outra parte que compõe o capital e que se refere aos meios de produção é chamada capital constante. O aumento do capital constante - pelo aumento da produtividade - provoca uma diminuição da demanda pela força de trabalho (Viana, 2006). 


\section{Referências}

ALVES, Giovanni. Dimensões da reestruturação produtiva: ensaios de sociologia do trabalho. Londrina: Praxis, 2007.

ALVES, Hayda; ESCOREL, Sarah. Massa marginal na América Latina: mudanças na conceituação e enfrentamento da pobreza 40 anos após uma teoria. Physis: Revista de Saúde Coletiva, Rio de Janeiro, v. 22, n. 1, p. 99-117, 2012.

ANTUNES, Ricardo. Quem é a classe trabalhadora de hoje?. Entrevista realizada pelo Sindicato dos Advogados do Estado de São Paulo com Ricardo Antunes. Seção Notícias/Notas rápidas. [2006]. Disponível em: <www.sasp.org.br/noticias/38-notasrapidas/83-entrevista-com-ricardo-antunes. html>. Acesso em: 08/11/2012.

BOSI, Antônio de P. A organização capitalista do trabalho 'informal': o caso dos catadores de recicláveis. Revista Brasileira de Ciências Sociais, São Paulo, v. 23, n. 67, p. 101-116, jun. 2008.

BRESSER-PEREIRA, Luiz Carlos. A reforma do Estado dos anos 90: lógica e mecanismos de controle. Lua Nova (on line): Revista de Cultura e Política, São Paulo, n. 45, p. 49-95, 1998. Disponível em: <www.scielo.br/pdf/ $\ln / \mathrm{n} 45 / \mathrm{a} 04 \mathrm{n} 45 . \mathrm{pdf}>$. Acesso em: 8 jan. 2012.

CARCANHOLO, Marcelo D.; AMARAL, Marisa S. Acumulação capitalista e exército industrial de reserva: conteúdo da superexploração do trabalho nas economias dependentes. ENCONTRO NACIONAL DE ECONOMISTAS MARXISTAS, 1., Curitiba, 30-31 de outubro, 2007. Disponível em: $<$ www.sitiodeeconomiapolitica.ufpr.br/ MarceloDiasCarcanholo_ MarisaSilvaAmaral. pdf>. Acesso em: 10 jan. 2013.

CARNEIRO, Carla B. L.; COSTA, Bruno L. D. Exclusão social e políticas públicas: algumas reflexões a partir das experiências descritas no programa gestão pública e cidadania.
Cadernos Gestão Pública e Cidadania, São Paulo, v. 28, EAESP/FGV, 2003. Disponível em: $<$ http://ceapg.fgv.br/sites/ceapg.fgv.br/files/ file/Cadernos/Cad28.pdf $>$. Acesso em: 2 mar. 2012.

ESCOREL, Sarah. Vidas ao léu: trajetória de exclusão social. Rio de Janeiro: Editora Fiocruz, 1999.

FERRAZ, Deise L. da S. Desemprego, exército de reserva, emprego formal-informal: rediscutindo categorias. 275 fls. Tese (Doutorado em Administração) - Universidade Federal do Rio Grande do Sul, Porto Alegre, 2010.

FONTES, Virginia. O Brasil e o capital-imperialismo: teoria e história. Rio de Janeiro: Escola Politécnica de Saúde Joaquim Venâncio/Editora UFRJ, 2010.

O imperialismo tardio: expropriações, trabalho, política e cultura. [2007]. Disponível em: <www.odiario.info/b2-img/ 2007-09-TEX\% 20Paris-Serpa.pdf>. Acesso em: 18 out. 2012.

FRIGOTTO, Gaudêncio. Exclusão e/ou desigualdade social? Questões teóricas e político-práticas. Cadernos de Educação, Pelotas, n. 37, p. 417-442, set./dez. 2010. Disponível em: <http://periodicos.ufpel.edu. br/ojs2/index.php/caduc/article/viewFile/ 1593/1479>. Acesso em: 17 out. 2012.

GUARESCHI, Pedrinho A. Pressupostos psicossociais da exclusão: competitividade e culpabilização. In: SAWAIA, Bader (Org.). As artimanhas da exclusão: análise psicossocial e ética da desigualdade social. Petrópolis: Vozes, p. 141-156, 2001. Disponível em: $<$ http://blogpsicologiablog.files.wordpress. com/2011/09/as-artimanhas-da-exclusc3a3osawaia-org.pdf>. Acesso em: 14 dez. 2012.

LEAL, Giuliana F. A noção de exclusão social em debate: aplicabilidade e implicações para a intervenção prática. Trabalho apresentado no XIV Encontro Nacional de Estudos 
Populacionais, Caxambu: ABEP, set. 2004. Disponível em: <www.abep.nepo.unicamp. br/site_eventos_abep/PDF/ABEP2004_42. pdf>. Acesso em: 18 dez. 2012.

NASCIMENTO, Elimar P. do. Hipóteses sobre a nova exclusão social: dos excluídos necessários aos excluídos desnecessários. Cadernos $C R H$, Salvador, n. 21, p. 29-47, jul./dez. 1994. Disponível em: <www.cadernocrh. ufba.br/include/getdoc.php?id=1177\& article $=315 \& \mathrm{~m}>$. Acesso em 12 jan. 2013.

NETTO, José Paulo. Uma face contemporânea da barbárie. ENCONTRO INTERNACIONAL 'CIVILIZAÇÃO OU BARBÁRIE', 3. Serpa, 2010. Disponível em: <www.pcb.org.br/portal/docs/ umafacecontemporaneadabarbarie.pdf $>$. Acesso em: 12 abr. 2013.

NUN, José. O futuro do emprego e a tese da massa marginal. Novos Estudos, São Paulo, v. 1, n. 56, p. 43-62, março de 2000. Disponível em: <http://novosestudos.uol.com.br/vl/ files/uploads/contents/90/20080627_o_ futuro_do_emprego.pdf $>$. Acesso em: 10 jan. 2013.

POCHMANN, Marcio. Proteção social na periferia do capitalismo: considerações sobre o Brasil. Revista São Paulo em Perspectiva, São Paulo, v. 18, n. 2, p. 3-16, abril./jun. 2004. Disponível em: <www. seade.gov.br/produtos/spp/v18n02/v18n2_ 01.pdf>. Acesso em: 10 mar. 2012.

STEREN DOS SANTOS, Tania. Globalização e exclusão: a dialética da mundialização do capital. Sociologias (on line), Porto Alegre, ano 3, n. 6, p. 170-198, jul./dez. 2001. Disponível em: <www.redalyc.org/articulo. oa? $\mathrm{id}=86819569008>$. Acesso em: 15 jan. 2012.

SAWAIA, Bader. Introdução: exclusão ou inclusão perversa? In: SAWAIA, Bader (Org.). As artimanhas da exclusão: análise psicossocial e ética da desigualdade social. Petrópolis: Vozes, 2001. p. 7-13. Disponível em: $<$ http://blogpsicologiablog.files. wordpress. com/2011/09/as-artimanhas-da-exclusc3a3osawaia-org.pdf>. Acesso em: 14 dez. 2012.
SPOSATI, Aldaíza. Exclusão social abaixo da linha do Equador. SEMINÁRIO EXCLUSÃO SOCIAL, 23 abr. 1998. Pontifícia Universidade Católica, São Paulo. Disponível em: <www.seuvizinhoestrangeiro.ufba.br/ twiki/pub/GEC/RefID/exclusao.pdf $>$. Acesso em: 12 nov. 2012.

SPOSATI, Aldaíza et al. Mapa da exclusão: inclusão social. 2002. Disponível em: <www. comciencia.br/reportagens/ppublicas/ppl1. htm>. Acesso em: 14 dez. 2012.

VERAS, Maura P. B. Exclusão social: um problema de 500 anos. Notas preliminares. In: SAWAIA, Bader (Org.). As artimanhas da exclusão: análise psicossocial e ética da desigualdade social. Petrópolis: Vozes, p. 27-50, 2001. Disponível em: <http://blogpsicologiablog. files.wordpress.com/2011/09/as-artimanhasda-exclusc3a3o-sawaia-org.pdf $>$. Acesso em: 14 dez. 2012.

VIANA, Nildo. A teoria da população em Marx. Boletim Goiano de Geografia, Goiânia, v. 26 n. 2 p. 87-102 jul./dez. 2006. Disponível em: <www.revistas.ufg.br/index.php/bgg/ article/view/4142/3644>. Acesso em: 1 jan. 2013.

WANDERLEY, Mariangela B. Refletindo sobre a noção de exclusão. In: SAWAIA, Bader (Org.). As artimanhas da exclusão: análise psicossocial e ética da desigualdade social. Petrópolis: Vozes, p. 16-26 2001. Disponível em: $<$ http://blogpsicologiablog.files.wordpress. com/2011/09/as-artimanhas-da-exclusc3a3osawaia-org.pdf>. Acesso em: 14 dez. 2012.

ZIONI, F. Exclusão social: noção ou conceito?. Saúde e Sociedade, São Paulo, v. 15, n. 3, p. 15-29, set/dez., 2006.

Recebido em 31/10/2013

Aprovado em 11/02/2014 
Onde se lê, no volume 12, número 2, pág. 231, o título "Circularidade perversa da exclusão-inclusão no Brasil contemporâneo", leia-se "Exclusão-inclusão: circularidade perversa no Brasil contemporâneo"; Onde se lê "Perverse circularity of exclusion-inclusion in contemporary Brazil", leia-se "Exclusion-inclusion: vicious circularity in contemporary Brazil", onde se lê "Círculo perverso de exclusión-inclusión en el Brasil contemporáneo", leia-se "Exclusión-inclusión: círculo perverso en el Brasil contemporâneo". 